\title{
Deferasirox: appraisal of safety and efficacy in long-term therapy
}

This article was published in the following Dove Press journal:

Journal of Blood Medicine

2 August 2013

Number of times this article has been viewed

\section{Preeti Chaudhary Vinod Pullarkat \\ Jane Ann Nohl Division of Hematology, University of Southern California Keck School of Medicine, Los Angeles, CA, USA}

\begin{abstract}
Deferasirox is a once-daily, oral iron chelator that is widely used in the management of patients with transfusional hemosiderosis. Several Phase II trials along with their respective extension studies as well as a Phase III trial have established the efficacy and safety of this novel agent in transfusion-dependent patients with $\beta$-thalassemia, sickle-cell disease and bone marrow-failure syndromes, including myelodysplastic syndrome and aplastic anemia. Data from various clinical trials show that a deferasirox dose of $20 \mathrm{mg} / \mathrm{kg} /$ day stabilizes serum ferritin levels and liver iron concentration, while a dose of $30-40 \mathrm{mg} / \mathrm{kg} /$ day reduces these parameters and achieves negative iron balance in red cell transfusion-dependent patients with iron overload. Across various pivotal clinical trials, deferasirox was well tolerated, with the most common adverse events being gastrointestinal disturbances, skin rash, nonprogressive increases in serum creatinine, and elevations in liver enzyme levels. Longer-term extension studies have also confirmed the efficacy and safety of deferasirox. However, it is essential that patients on deferasirox therapy are monitored regularly to ensure timely management for any adverse events that may occur with long-term therapy.
\end{abstract}

Keywords: deferasirox, iron overload, thalassemia, sickle-cell disease, myelodysplastic syndrome

\section{Introduction}

Iron overload contributes significantly to morbidity and mortality in patients receiving regular red blood-cell transfusions as supportive therapy for chronic anemias such as $\beta$-thalassemia, sickle-cell disease (SCD), and myelodysplastic syndromes (MDSs). In the absence of physiological mechanisms to excrete this excess iron resulting from transfusions, administration of effective iron-chelation therapy that results in net negative iron balance is the only way to prevent end-organ damage from iron deposition in various tissues. While deferoxamine (DFO) is an effective iron chelator that has been shown to improve survival in iron-overloaded $\beta$-thalassemia patients, its delivery and compliance with therapy are less than ideal. ${ }^{1}$ DFO is typically administered as a subcutaneous infusion over 8-24 hours, 5-7 days per week, delivered overnight by a small portable pump. ${ }^{2}$ This arduous schedule interferes with patients' quality of life and results in poor patient compliance. ${ }^{3}$ The urgent need for an effective and safe oral iron chelator led to the expedited approval of deferasirox (Exjade ${ }^{\circledR}$, Novartis Pharmaceuticals Corporation, Basel, Switzerland) by the US Food and Drug Administration (FDA) in November 2005 for the treatment of transfusional iron overload associated with thalassemia and other iron-loading conditions with an orphan-drug designation. ${ }^{4}$ Deferiprone, another orally bioavailable iron chelator, has been shown to be safe
Correspondence: Vinod Pullarkat Jane Ann Nohl Division of Hematology, University of Southern California Keck School of Medicine, 144I Eastlake Avenue, MC 9172, NOR 346I, Los Angeles, CA 90033, USA

$\mathrm{Tel}+\mathrm{I} 3238653848$

Fax +I 3238650060

Email vinod.pullarkat@med.usc.edu 
and efficacious in iron-overloaded $\beta$-thalassemia patients. Although it was being used in other countries, deferiprone received FDA approval only in October 2011 for treatment of patients with transfusional iron overload due to thalassemia syndromes who were not adequately chelated with other agents. However, the use of deferiprone has been limited, due to the occurrence of rare but serious adverse events during treatment, such as neutropenia and agranulocytosis.,

This review will focus on the long-term safety and efficacy of deferasirox in trials conducted for transfusional hemosiderosis in hemoglobinopathies and bone marrowfailure syndromes.

\section{Pharmacology of deferasirox}

Deferasirox is a tridentate chelator with a long halflife of 8-16 hours, allowing for convenient once-daily administration. ${ }^{7}$ It is rapidly absorbed, and has a bioavailability of about $70 \%$. It is mainly excreted in the feces $(84 \%$ of the dose) after it is metabolized by glucuronidation and subsequent biliary excretion. ${ }^{8}$ The highest dose of deferasirox approved by most health authorities is $30 \mathrm{mg} / \mathrm{kg} /$ day. However, most recently the FDA and European Medicines Agency have approved doses up to $40 \mathrm{mg} / \mathrm{kg} /$ day in patients not adequately chelated with doses of $30 \mathrm{mg} / \mathrm{kg} /$ day; doses above $40 \mathrm{mg} / \mathrm{kg} /$ day are generally not recommended. ${ }^{4,9}$ The efficacy and safety of deferasirox were initially studied in a series of 1-year Phase II and III clinical trials involving more than 1,000 patients. In order to assess its long-term efficacy and safety, 4-year extension Phases of the 1-year core trials were conducted (Table 1). Results from the extension Phases, with a median follow-up of 5 years now, have confirmed the efficacy of deferasirox to be dose- and transfusiondependent. ${ }^{10}$ Across these clinical trials, deferasirox was well tolerated, with the most common drug-related adverse events being mild to moderate in severity and often self-limiting (Table 1). Serious albeit rare adverse effects reported with long-term deferasirox use include renal failure, agranulocytosis, hepatic toxicity, and gastrointestinal bleeding, making close toxicity monitoring mandatory. ${ }^{11}$

\section{Thalassemia}

Thalassemia, first described by Cooley and Lee in 1925, is a hereditary form of anemia resulting from an imbalance in the synthesis of the $\alpha$ - and $\beta$-chains of hemoglobin leading to hemolysis and ineffective erythropoiesis. ${ }^{12}$ Iron overload in patients with thalassemia is mainly the result of regular red blood-cell transfusions and can result in an iron load of up to 10 g per year. ${ }^{13}$ Iron overload can also result from increased intestinal iron absorption, particularly in patients with thalassemia intermedia. ${ }^{14}$ Patients who receive regular blood transfusions without adequate chelation therapy develop evidence of iron excess (elevated liver iron concentration [LIC] and serum ferritin) within 1-2 years of transfusion therapy. Adequate iron chelation with DFO from early on in life in these iron-overloaded $\beta$-thalassemia patients has significant benefits on both morbidity and early mortality. ${ }^{15,16}$ Unfortunately, effective administration of ironchelation therapy with DFO is often compromised secondary to the arduous schedule of overnight subcutaneous infusions leading to reduced compliance. ${ }^{17}$ DFO is also associated with local skin reactions, ophthalmological adverse effects (optic neuropathy, retinal pigmentation), ototoxicity, anaphylactic reactions, pulmonary fibrosis, and rarely renal impairment. ${ }^{18,19}$

In various trials done to date, deferasirox has proved to be an effective, safe oral iron-chelating agent in patients with thalassemia. The results of two initial short-term studies investigating mainly the safety and pharmacokinetics of deferasirox were reported by Galenello et $\mathrm{al}^{20}$ and NisbetBrown et al. ${ }^{21}$ Following their results, further clinical testing in Phase II and III trials was performed. Piga et al conducted a randomized open-label Phase II trial in $71 \beta$-thalassemia patients focusing mainly on safety of deferasirox. Efficacy was judged to be comparable for $20 \mathrm{mg} / \mathrm{kg} /$ day of deferasirox and $40 \mathrm{mg} / \mathrm{kg} /$ day of DFO, supporting the assumed 1:2 equivalence ratio. ${ }^{22}$

In a subsequent large Phase III comparative trial, patients with $\beta$-thalassaemia major were randomized to receive either deferasirox (296 patients) or DFO (290 patients), dosed according to their baseline LIC. This was a noninferiority trial that led to the approval of deferasirox in the US. Over 1 year, a deferasirox dose of $20 \mathrm{mg} / \mathrm{kg} /$ day stabilized the mean serum ferritin level close to $2,000 \mathrm{ng} / \mathrm{mL}$, achieved negative iron balance, and maintained LIC. Maintenance of LIC at $7 \mathrm{mg}$ iron/g dry weight was achieved in $59.7 \%$ of patients in the deferasirox arm versus $58.7 \%$ of patients in the DFO arm. For both drugs, a clear dose-effect relationship was noted. A deferasirox dose of $30 \mathrm{mg} / \mathrm{kg} /$ day reduced serum ferritin by about $1,200 \mathrm{ng} / \mathrm{mL}$ and achieved negative iron balance, with a fall in LIC of $8.9 \mathrm{mg}$ iron/g dry weight over 1 year, whereas lower doses of deferasirox were not as effective and led to a positive iron balance in most patients. ${ }^{23}$ Transient gastrointestinal disturbances, including abdominal pain, nausea, vomiting, diarrhea, and constipation, were reported in $15.2 \%$ of patients. Mild, dose-dependent increases in serum creatinine were noted in $38 \%$ of patients on deferasirox; however, only $13 \%$ of 


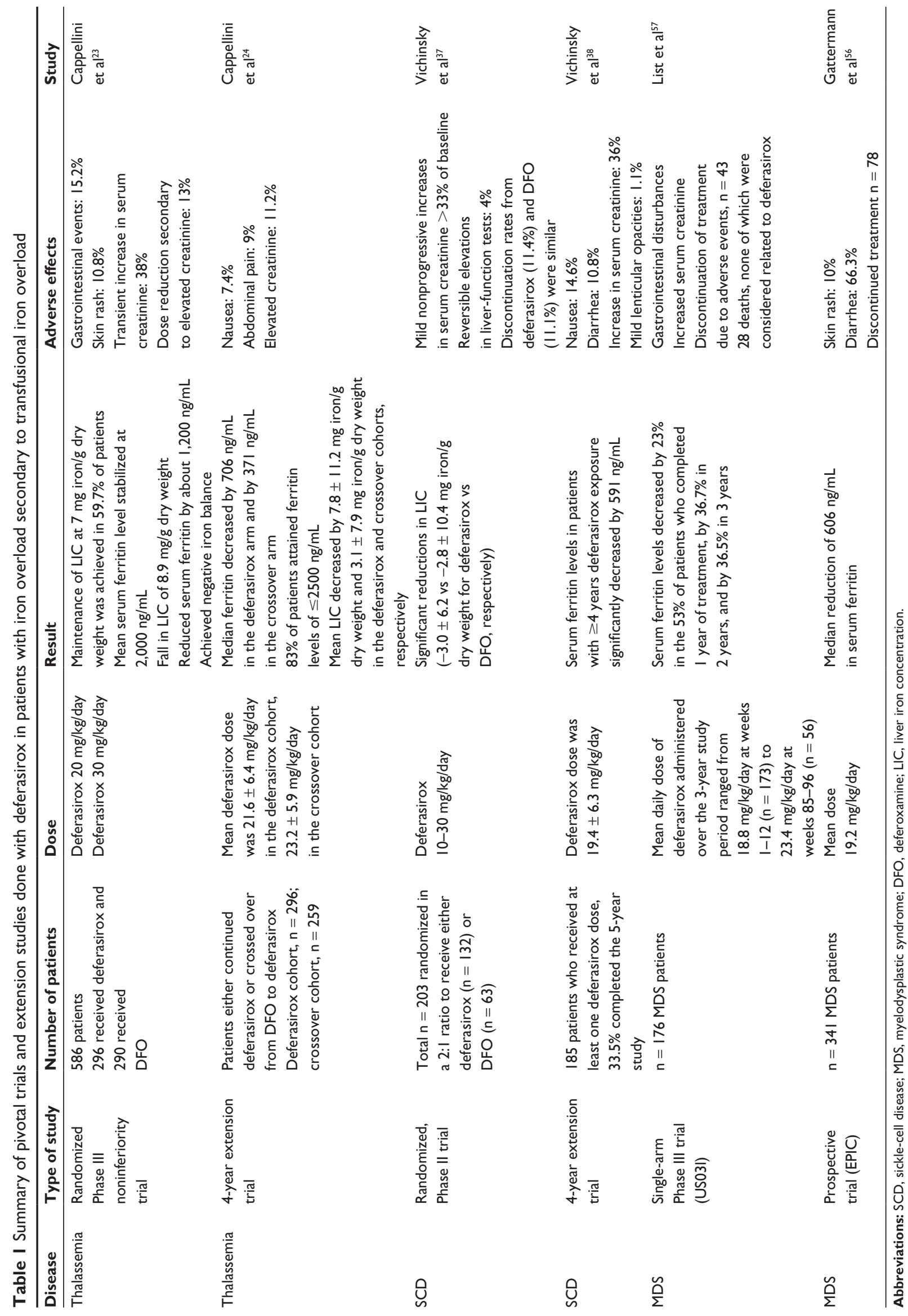


patients required dose reduction, as creatinine spontaneously normalized in a number of patients. Among patients who required dose reduction, creatinine returned to baseline in $25 \%$ of patients, and in the rest either remained stable or fluctuated between baseline and the maximum increase observed prior to dose adjustment. Despite fluctuations in serum copper and zinc levels, no patient developed trace-element deficiency in the trial. As expected, satisfaction with and convenience of deferasirox treatment was significantly higher, although this was not reflected in the rate of discontinuation of deferasirox when compared to DFO.

In order to evaluate the long-term efficacy and safety of deferasirox in patients with $\beta$-thalassemia who completed the 1-year trial, a 4-year extension study was conducted. ${ }^{24}$ In this extension trial, patients either continued receiving deferasirox (deferasirox cohort) or crossed over from DFO to deferasirox (crossover cohort). Overall, two-thirds of the patients completed the 5-year study. The results were reassuring, as irrespective of whether patients switched from DFO or continued on deferasirox, significant decreases in both LIC and serum ferritin levels were observed. Median serum ferritin significantly decreased by $706 \mathrm{ng} / \mathrm{mL}$ in the deferasirox arm and by $371 \mathrm{ng} / \mathrm{mL}$ in the crossover arm. Serum ferritin levels of $\leq 2,500 \mathrm{ng} / \mathrm{mL}$ were attained in $83 \%$ of patients. Mean LIC significantly decreased by $7.8 \pm 11.2 \mathrm{mg}$ iron/g dry weight and $3.1 \pm 7.9 \mathrm{mg}$ iron/g dry weight in the deferasirox and crossover cohorts, respectively. Deferasirox was generally well tolerated over the long term in both pediatric and adult patients. No adverse effects on growth and development were noted in younger patients on deferasirox treatment. Gastrointestinal adverse effects (9\%) and increased serum creatinine (11\%) were transient and mild to moderate in severity. Renal and liver functions were closely monitored during the trial, and no progressive increases in serum creatinine or liver transaminase levels were observed during long-term deferasirox treatment. Long-term safety of iron chelators is critical in $\beta$-thalassemia patients, since most require lifelong red cell transfusions and therefore iron-chelation therapy. This is particularly relevant in pediatric populations, as intensive chelation therapy initiated to prevent iron toxicity can cause growth deceleration and skeletal changes. ${ }^{25}$ Long-term consequences of deferasirox on growth and development in chelation-naïve children below 5 years of age were explored in an observational study. Deferasirox was found to be an effective first-line therapy to maintain negative iron balance without adverse effects on growth and development in this age-group. ${ }^{26}$

The efficacy of deferasirox in reducing cardiac iron and thereby preventing cardiac iron loading was assessed using cardiovascular magnetic resonance by measuring myocardial $T_{2} *$ in a subgroup of patients with $\beta$-thalassemia $(n=192)$ who were enrolled in the large Evaluation of Patients' Iron Chelation with Exjade (EPIC) trial. ${ }^{27} \mathrm{~A}$ cardiac $T_{2}{ }^{*}$ value of $<20 \mathrm{~ms}$ is considered to indicate cardiac iron levels below the normal range, whereas a value $<10 \mathrm{~ms}$ is associated with reduction in left and right ventricular ejection fraction and an increased risk of cardiac failure and arrhythmia. Results of this study were significant for marginal but statistically significant improvement in myocardial $T_{2} *$ in the treatment arm, improved from a baseline of $11.2 \mathrm{~ms}( \pm 40.5 \%)$ to $12.9 \mathrm{~ms}( \pm 49.5 \%)$ with maintained left ventricular function, while in patients without cardiac iron overload (prevention arm), the ejection fraction improved significantly. Seventyone patients from this study elected to continue deferasirox and entered the 3-year extension phase. Over the 3 years of follow-up, myocardial $T_{2}{ }^{*}$ increased significantly from $12.0 \mathrm{~ms} \pm 39.1 \%$ at baseline to $17.1 \mathrm{~ms} \pm 62.0 \%$ at the end of the study, corresponding to a continued reduction in cardiac iron concentration from $2.43 \pm 1.2 \mathrm{mg}$ iron $/ \mathrm{g}$ dry weight at baseline to $1.80 \pm 1.4 \mathrm{mg}$ iron/g dry weight at the end of the study. Mean deferasirox doses were high $(33.6 \pm 9.8 \mathrm{mg} / \mathrm{kg} /$ day), with no increase in adverse effects noted. ${ }^{28}$ In another study of 19 patients, significant improvements of myocardial $T_{2}^{*}$ were demonstrated in heavily transfused iron-overloaded patients who demonstrated greater than $95 \%$ compliance to therapy with deferasirox, reiterating the fact that compliance is essential for success of treatment in myocardial siderosis. ${ }^{29}$ Deugnier et al reported long-term effects of deferasirox treatment on liver fibrosis, and found that deferasirox treatment for 3 or more years reversed or stabilized liver fibrosis and necroinflammation in $83 \%$ of patients with iron-overloaded $\beta$-thalassemia. This therapeutic effect was independent of reduction in LIC. ${ }^{30}$

Another prospective, open-label, 1-year study, the ESCALATOR (Extension Study of the Efficacy and Safety of Deferasirox Treatment in Beta-thalassemia Patients with Transfusional Hemosiderosis) trial was conducted in the Middle East to evaluate the efficacy and safety of deferasirox in patients who had been previously treated with DFO and/or deferiprone. Mean baseline LIC in the study was $18.0 \pm 9.1 \mathrm{mg}$ iron $/ \mathrm{g}$ dry weight, while median serum ferritin was $3356 \mathrm{ng} / \mathrm{mL}$. After 1 year of deferasirox treatment, the intent-to-treat population experienced a significant mean reduction in LIC of $3.4 \mathrm{mg}$ iron/g dry weight and a decrease in median serum ferritin of $341 \mathrm{ng} / \mathrm{mL}$ at 52 weeks. Most patients (78.1\%) underwent dose increases above $20 \mathrm{mg} / \mathrm{kg} /$ day, mostly to $30 \mathrm{mg} / \mathrm{kg} /$ day. For reasons that 
are not so clear, reductions in serum ferritin and LIC were noted to be more pronounced in the adult population when compared to the pediatric population. Deferasirox was well tolerated overall, with manageable side effects and good safety profile, and there were no reported discontinuations due to adverse effects. There were no negative effects noted on physical or gonadal development in children; however, longer follow-up studies are needed to make such claims. Another important result of the study was a statistically significant improvement in left ventricular ejection fraction observed by week 52, suggesting a positive effect of deferasirox on cardiac function. ${ }^{31}$

\section{Sickle-cell disease}

Red cell-transfusion therapy has been shown effectively to prevent strokes and other complications, mainly acute chest syndrome, pain crisis, and growth retardation in SCD patients. ${ }^{32-34}$ Many patients with SCD have received multiple blood transfusions by adulthood. Unlike $\beta$-thalassemia, iron overload can be easily overlooked in SCD patients due to episodic requirements for red cell transfusions, even though these patients often develop iron-induced complications later in life similar to other chronically transfused populations. ${ }^{35}$ Therefore, guidelines from consensus panels have recommended iron-chelation therapy in SCD patients with evidence of iron overload. ${ }^{36}$ Current recommendations are to initiate iron-chelation therapy in patients with SCD once LIC increases to $\geq 7 \mathrm{mg}$ iron/g dry weight, if serum ferritin steadystate levels are $>1000 \mathrm{ng} / \mathrm{mL}$, or if patients have received cumulative transfusions of $120 \mathrm{~mL}$ packed red blood cells $/ \mathrm{kg}$ (USA) or at least 20 top-up transfusions (UK) (National Institutes of Health NHLBI, 2002; Sickle Cell Society, 2008). A major issue with the use of deferasirox in SCD patients who may have baseline compromised renal function was the concern for renal toxicity, which was seen in some preclinical studies done with the drug in animals. Another concern was the lack of knowledge on whether treatment with deferasirox would provoke or exacerbate sickle-cell crisis.

Vichinsky et al compared the safety and efficacy of deferasirox versus DFO in a 1-year, multicenter, open-label, randomized Phase II trial. In this trial, 203 eligible patients were randomized in a 2:1 ratio to receive either deferasirox or DFO. Deferasirox treatment resulted in statistically significant and similar reductions in LIC compared to DFO $(-3.0 \pm 6.2 \mathrm{vs}-2.8 \pm 10.4 \mathrm{mg}$ iron/g dry weight for deferasirox vs DFO, respectively). ${ }^{37}$ The most notable adverse effects irrespective of the relationship to study medication were transient gastrointestinal disturbances and skin rash.
In the deferasirox group, mild, stable increase in serum creatinine of unknown clinical relevance was noted in 36.4\% of patients. Despite greater satisfaction with deferasirox treatment, the rate of discontinuation of therapy was similar in both arms. In order to assess the long-term efficacy and safety of deferasirox in patients with SCD, patients who completed the 1-year study entered a 4-year extension Phase where they continued to receive deferasirox, or switched from DFO to deferasirox. ${ }^{38}$ Of the patients who received at least one dose of deferasirox, only 62 patients (33.5\%) completed the extension study; the reasons for such a high rate of discontinuation in SCD patients remain unclear. Another drawback of the study was the inability to assess the impact of deferasirox therapy on the frequency of sickle-cell crisis secondary to the lack of control group in the study design. However, serum ferritin levels in patients with $\geq 4$ years of deferasirox exposure significantly decreased by $591 \mathrm{ng} / \mathrm{mL}$, and the tolerability of the drug improved with long-term follow-up, as a decrease in the most common adverse effect was noted with continued therapy.

Cancado et al investigated the efficacy and safety of a 2-year treatment program with deferasirox in 31 patients with SCD and transfusional iron overload. Their results were similar to those reported in prior studies of $\beta$-thalassemia and SCD. At 24 months, there were significant decreases from baseline in mean serum ferritin (from 2,344.6 to $1,986.3 \mathrm{ng} / \mathrm{mL}$ ) and in mean LIC (from $13.0 \pm 5.4$ to $9.3 \pm 5.7 \mathrm{mg}$ iron/g dry weight). The authors also noted significantly improved left ventricular function at 24 months when compared to baseline, despite a statistically nonsignificant decline in myocardial mean $T_{2}{ }^{*}$ from baseline. The most common adverse effects in the study were transient and mild, with diarrhea and headaches reported in $22.6 \%$ patients each. Three patients $(9.5 \%)$ were noted to have nonprogressive increase in serum creatinine. ${ }^{39}$ Taken together, these studies support the efficacy of deferasirox in iron-overloaded SCD patients and demonstrate its safety over a reasonably long time period.

\section{Myelodysplastic syndromes}

The MDSs comprise a heterogeneous group of malignant hematopoietic stem cell disorders characterized by dysplastic and ineffective blood-cell production and a variable risk of transformation to acute leukemia. ${ }^{40}$ The major cause of iron overload in these patients is red cell transfusions for anemia. With every unit of transfused blood, the patients receive approximately 200-250 mg iron. ${ }^{41}$ Another less recognized cause of iron excess in MDS patients is increased absorption 
of iron from the gut due to ineffective erythropoiesis. ${ }^{42}$ Overall survival and leukemia-free survival are significantly shorter in transfusion-dependent MDS patients. ${ }^{43}$ This may simply be related to disease severity or be an effect of iron overload itself. Gattermann and Rachmilewitz noted shortened overall survival with increasing ferritin level, with a hazard ratio of 1.42 for every $500 \mathrm{ng} / \mathrm{mL}$ increase in ferritin over $1,000 \mathrm{ng} / \mathrm{ml} .{ }^{44}$ Even in patients undergoing hematopoietic stem cell transplantation (HSCT), elevated pre-transplant serum ferritin level adversely affects survival. ${ }^{45}$ Excess iron has also been shown to suppress erythropoiesis, as evidenced by decreased burst-forming units erythroid in patients with elevated ferritin compared to patients with normal ferritin. ${ }^{46}$ Thus, iron overload has many deleterious effects, especially in the usually older MDS population, with significant comorbidities that make them more sensitive to the effects of iron overload. ${ }^{47}$ As phlebotomy is not a feasible option in MDS patients, an effective way to prevent adverse consequences of iron overload is iron-chelation therapy. There are several published guidelines recommending chelation in chronically transfused MDS patients, mostly based on retrospective case-control studies and some prospective randomized supportive data extrapolated from other ironoverload disease populations. In this regard, the results of the ongoing TELESTO (Myelodysplastic Syndromes Event-Free Survival with Iron Chelation Therapy Study) trial, a placebocontrolled randomized trial in low- and intermediate-1-risk MDS patients, are much awaited. Currently, the main factors taken into account to make decisions about initiating iron chelation in MDS patients include life expectancy, transfusion burden, evidence of iron excess (elevated ferritin), and related comorbidities. Recommendation are that low-risk disease (low- or intermediate-1-risk International Prognostic Scoring System [IPSS]) with a life expectancy of 5 years, and either a serum ferritin level over $2000 \mathrm{mg} / \mathrm{L}$ or a transfusion intake of at least 20 units of packed red blood cells, or clinical, biopsy, or imaging evidence of iron overload and those who are eligible for hematopoietic stem cell transplantation should receive iron-chelation therapy. ${ }^{48-51}$

Porter et al have reported the results of a prospective Phase II trial that evaluated the efficacy of deferasirox in 184 regularly transfused patients, including 47 MDS patients. ${ }^{52}$ Overall, the results of the trial showed that there were no significant statistical differences between disease groups in terms of response to iron-chelation therapy, and that liver LIC changes were dependent on dose and transfusion iron intake. Change in serum ferritin in relation to the change in LIC followed a similar trend for all disease groups treated with the drug. In this trial, changes in LIC were more pronounced in the MDS subgroup of patients, even though these patients had the lowest transfusion iron intake. In another small study of 20 MDS patients by Metzegeroth et al, deferasirox was effective in reducing ferritin concentration; however, the authors noted that $70 \%$ of the patients had an increase in ferritin levels during the first 4 weeks of deferasirox therapy, and hence concluded that serum ferritin levels may not be very reliable for dose escalation earlier in the treatment course. ${ }^{53}$ Wimazal et al reported efficacy of deferasirox in 14 MDS patients treated for up to 24 months. All patients except one demonstrated decreased ferritin levels during therapy, with four patients achieving a complete response..$^{54}$

In a recent multicenter trial, Nolte et al evaluated the efficacy and safety of deferasirox (mean daily trial dose $19 \mathrm{mg} / \mathrm{kg}$ ) in 50 low- or intermediate-1-risk (IPSS) MDS patients. A significant reduction of ferritin and mean LIC was reported after 1 year of treatment. Hematological improvement was reported in six patients $(11 \%) .^{55}$

The largest prospective trial to date (EPIC) enrolled 341 MDS patients among a total of 1,744 patients. The overall mean average dose during treatment was $19.2 \mathrm{mg} / \mathrm{kg} /$ day . Serum ferritin levels decreased significantly from baseline after 1 year of treatment, with a median reduction of $606 \mathrm{ng} / \mathrm{mL}$. Responses were seen in both pretreated and chelation-naïve patients. However, only about $52 \%$ of the MDS patients were able to complete 1 year of treatment, with about $13 \%$ of the patients discontinuing due to adverse effects. ${ }^{56}$ The second-largest trial (US03) was an open-label, single-arm, Phase III trial that included 176 MDS patients. In this trial, median serum ferritin levels decreased by $23 \%$ in the $53 \%$ of patients who completed 12 months of treatment, by $36.7 \%$ in patients who completed 2 years, and by $36.5 \%$ in patients who completed 3 years, despite continued transfusion requirements. Over 1 year of deferasirox treatment, lineage-specific improvements in hematologic parameters were noted in $15 \%-22 \%$ of patients, suggesting that hematologic improvement may occur with chelation therapy in MDS patients. Reduction in serum ferritin significantly correlated with alkaline phosphate improvement, a finding also noted in the EPIC trial. ${ }^{56,57}$

Across these clinical trials, the most common toxicities reported in up to $45 \%$ of MDS patients were gastrointestinal symptoms, including diarrhea, nausea, vomiting, and abdominal pain, which may be partly related to the presence of lactose in the formulation of deferasirox. ${ }^{52,53}$ Skin rash was reported in about $9 \%$ of patients and nonprogressive 
transient increase in serum creatinine has also been commonly reported. In the EPIC trial, apart from the usual gastrointestinal and skin toxicities, hearing loss and lens opacities were uncommonly reported. ${ }^{56}$ In the eXtend and eXjange studies, among the 335 treatment-naïve and prechelated MDS patients enrolled, seven of them (five naïve and two prechelated) experienced serious adverse effects, including gastrointestinal bleeding, myocardial infarction, neutropenia, lens opacity, and acute renal failure. ${ }^{58}$ In the US03 trial, the rate of drug discontinuation due to adverse effects was reported as $24.8 \%$, most commonly related to gastrointestinal disturbances and creatinine increases. ${ }^{57}$ Iron chelation with deferasirox in MDS patients seems to have favorable effects on hematopoiesis in a subset of patients with about $28 \%$ low- and intermediate-1-grade MDS patients having hematological improvement by International Working Group criteria in the US03 trial. In the post hoc analysis evaluating hematological response to deferasirox therapy in the iron-overloaded MDS patient cohort enrolled in the EPIC trial, improvement in hematologic parameters with an overall erythroid response was noted in $21.5 \%$ of the patients, platelet response in $13.0 \%$ of the patients, and neutrophil response in $22.0 \%$ of the patients. ${ }^{59}$ With its confirmed efficacy and acceptable safety profile, deferasirox is a reasonable option for selected iron-overloaded MDS patients. However, particular attention should be paid to toxicity monitoring in this group of patients, most of whom are elderly with significant comorbidities and side effects from other concomitant therapies for MDS.

There is evidence from registry data as well as retrospective analyses that iron chelation improves overall survival and delays time to development of acute myeloid leukemia in patients with MDS. ${ }^{60,61}$ If these findings are confirmed in prospective studies like the TELESTO trial mentioned previously, iron chelation may prove to be a disease-modifying therapy for MDS.

The EPIC trial also enabled evaluation of efficacy of chelation therapy in patients with aplastic anemia $(n=116)$. At a mean deferasirox dose of $17.6 \mathrm{mg} / \mathrm{kg} /$ day, there was a significant reduction in serum ferritin by $964 \mathrm{ng} / \mathrm{mL}$. The most common toxicities reported in this patient population were nausea, diarrhea, and skin rash. There were no reported progressive increases in serum creatinine or hepatic transaminases. ${ }^{62}$ In addition, a post hoc analysis of the EPIC trial has shown hematologic responses in eleven of 24 patients who received deferasirox as sole therapy. ${ }^{63}$ The efficacy of deferasirox has also been demonstrated in Diamond-Blackfan anemia and Fanconi anemia. ${ }^{52,64}$

\section{Nontransfusional iron overload}

Iron overload in hereditary hemochromatosis $(\mathrm{HH})$ results from increased iron absorption from the gut. Although phlebotomy is effective and remains the preferred treatment for $\mathrm{HH}$, oral iron chelation may be required in some patients due to factors like poor venous access, concurrent anemia, or patient preference. Deferasirox is not FDA-approved for treatment of iron overload in HH. In a Phase I/II trial in which a total of 49 patients with $H F E$-related $\mathrm{HH}$ were treated with 5,10 , or $15 \mathrm{mg} / \mathrm{kg}$ of deferasirox daily, serum ferritin levels declined by $63.5 \%, 74.8 \%$, and $74.1 \%$ in the 5 , 10 , and $15 \mathrm{mg} / \mathrm{kg}$ cohorts, respectively, at 48 weeks. Seven patients discontinued treatment due to adverse effects. In this study, $10 \mathrm{mg} / \mathrm{kg} /$ day was the best-tolerated and most effective dose. ${ }^{65}$

Localized iron overload in the brain is implicated in the pathogenesis of some neurodegenerative disorders. ${ }^{66}$ However, no systematic trials of deferasirox or other iron chelators have been performed for these conditions.

\section{Management of adverse effects of deferasirox}

In order to achieve effective iron chelation with minimal toxicity in individual patients, regular monitoring to assess iron overload and adverse effects of deferasirox treatment is essential. Despite marked day-to-day variations, serum ferritin levels correlate well with LIC. Based on monthly measurements of serum ferritin, doses of deferasirox can be adjusted every 3-6 months if required, with accurate and careful assessment of toxicity profiles.

In clinical evaluation of deferasirox, the most commonly reported adverse effect was transient, mild to moderate gastrointestinal disturbance, which tended to occur early in the course of the treatment. Abdominal pain has been reported in about $5 \%$ of patients. ${ }^{23}$ It is recommended to avoid concomitant use of aluminum-containing antacids, nonsteroidal anti-inflammatory drugs, and narcotics with deferasirox. It is also helpful to advise patients to take the medication at bedtime with sips of water. In cases with persistent gastrointestinal side effects, splitting the total daily dose into two doses or changing the medium in which tablets are dissolved (water, apple juice, or orange juice) may be helpful. Adequate hydration also helps with nausea associated with the drug. In the majority of patients, diarrhea is self-limiting or can be easily managed with antidiarrheal treatments. Drug interruption may be required in patients in whom diarrhea persists for more than 2 weeks. 
Deferasirox can be continued without dose adjustment in cases of mild rashes, as the majority resolve spontaneously. In cases of severe rash, deferasirox therapy should be interrupted and reintroduced at a lower dose. Some investigators have utilized low-dose prednisone in the management of rash; doses of $5 \mathrm{mg}$ in children and $10 \mathrm{mg}$ in adults for a maximum of 1 month can be considered. Serum creatinine levels should be regularly monitored with special attention in patients with SCD who may have compromised baseline renal function. Increases in serum creatinine may be related to overchelation. About $2 \%$ of patients developed elevations in serum transaminases, unrelated to dose of deferasirox. Liverfunction tests should be obtained prior to initiation of therapy and at regular intervals thereafter. Auditory and ocular adverse events with deferasirox are rare; however, it is recommended that patients be monitored at baseline and annually during treatment. ${ }^{26}$ Serious adverse effects may require termination of deferasirox in about $10 \%$ of patients. ${ }^{67}$

\section{Conclusion}

Chronic iron overload is a serious condition that necessitates close monitoring and effective chelation therapy in order to prevent long-term complications. The availability of deferasirox is a major milestone in iron-chelation therapy, and has made such therapy convenient for a large number of patients. There is enough evidence from various pivotal clinical trials and subsequent extension studies validating the efficacy and safety of deferasirox for the treatment of iron-overloaded, regularly transfused patient populations, including those with thalassemia, SCD, MDS, and other rare anemias, including aplastic anemia. However, even longer follow-up is needed to establish fully the long-term efficacy and toxic side effects of deferasirox, particularly in patients with hemoglobinopathies, who are likely to be receiving deferasirox therapy for decades.

\section{Disclosure}

Vinod Pullarkat has served on speakers' bureaus and advisory boards for Novartis. Preeti Chaudhary has no conflicts of interest to declare.

\section{References}

1. Borgna-Pignatti C, Rugolotto S, De Stefano P, et al. Survival and complications in patients with thalassemia major treated with transfusion and deferoxamine. Haematologica. 2004;89(10):1187-1193.

2. Novartis Pharmaceuticals. Desferal [package insert]. East Hanover (NJ): Novartis Pharmaceuticals; 2002.

3. Delea TE, Edelsberg J, Sofrygin O, et al. Consequences and costs of noncompliance with iron chelation therapy in patients with transfusiondependent thalassemia: a literature review. Transfusion. 2007;47(10): 1919-1929.
4. Novartis Pharmaceuticals. Exjade (deferasirox) tablets for oral suspension [prescribing information]. East Hanover (NJ): Novartis Pharmaceuticals; 2006.

5. Cohen AR, Galanello R, Piga A, De Sanctis V, Tricta F. Safety and effectiveness of long-term therapy with the oral iron chelator deferiprone. Blood. 2003;102(5):1583-1587.

6. Ceci A, Baiardi P, Felisi M, et al. The safety and effectiveness of deferiprone in a large-scale, 3-year study in Italian patients. Br J Haematol. 2002;118(1):330-336.

7. Nick H, Acklin P, Lattmann R, et al. Development of tridentate iron chelators: from desferrithiocin to ICL670. Curr Med Chem. 2003;10(12): $1065-1076$.

8. Nick H, Wong A, Acklin P, et al. ICL670A: preclinical profile. $A d v$ Exp Med Biol. 2002;509:185-203.

9. Nisbet-Brown E, Olivieri NF, Giardina PJ, et al. Effectiveness and safety of ICL670 in iron-loaded patients with thalassaemia: a randomised, double-blind, placebo-controlled, dose-escalation trial. Lancet. 2003;361(9369):1597-1602.

10. Cappellini MD, Vichinsky E, Galanello R, et al. Long-term treatment with deferasirox (Exjade, ICL670), a once-daily oral iron chelator, is effective in patients with transfusion-dependent anemias. Blood. 2007;110(11):2777.

11. Kontoghiorghes GJ. Deferasirox: uncertain future following renal failure fatalities, agranulocytosis and other toxicities. Expert Opin Drug Saf. 2007;6(3):236-239.

12. Cooley TB, Lee P. A series of cases of splenomegaly in children with anemia and peculiar bone changes. Trans Am Pediatr Soc. 1925;37: $29-30$.

13. Kushner JP, Porter JP, Olivieri NF. Secondary iron overload. Hematology Am Soc Hematol Educ Program. 2001:47-61.

14. Taher A, Isma'eel H, Cappellini MD. Thalassemia intermedia: revisited. Blood Cells Mol Dis. 2006;37(1):12-20.

15. Gabutti V, Piga A. Results of long-term iron-chelating therapy. Acta Haematol. 1996;95(1):26-36.

16. Zurlo MG, De Stefano P, Borgna-Pignatti C, et al. Survival and causes of death in thalassaemia major. Lancet. 1989;2(8653):27-30.

17. Cappellini MD. Overcoming the challenge of patient compliance with iron chelation therapy. Sem Hematol. 2005;42(2 Suppl 1):19-21.

18. Freedman MH, Grisaru D, Olivieri N, MacLusky I, Thorner PS. Pulmonary syndrome in patients with thalassemia major receiving intravenous deferoxamine infusions. Am J Dis Child. 1990;144(5): $565-569$.

19. Koren G, Kochavi-Atiya Y, Bentur Y, Olivieri NF. The effects of subcutaneous deferoxamine administration on renal function in thalassemia major. Int J Hematol. 1991;54(5):371-375.

20. Galanello R, Piga A, Alberti D, Rouan MC, Bigler H, Séchaud R. Safety, tolerability, and pharmacokinetics of ICL670, a new orally active iron-chelating agent in patients with transfusion-dependent iron overload due to beta thalassemia. J Clin Pharmacol. 2003;43(6): $565-572$.

21. Nisbet-Brown E, Olivieri NF, Giardina PJ, et al. ICL670A, a tridentate orally-active iron chelator, provides net negative iron balance and increased serum iron binding capacity in iron-overloaded patients with thalassemia. Blood. 2001;98(11 Pt 1):747.

22. Piga A, Galanello R, Cappellini M, et al. Phase II study of oral chelator ICL670 in thalassaemia patients with transfusional iron overload: efficacy, safety, pharmacokinetics (PK) and pharmacodynamics (PD) after 6 months of therapy. Blood. 2002;100(11 Pt 1):5a.

23. Cappellini MD, Cohen A, Piga A, et al. A Phase 3 study of deferasirox (ICL670), a once-daily oral iron chelator, in patients with betathalassaemia. Blood. 2006;107(9):3455-3462.

24. Cappellini MD, Bejaoui M, Agaoglu L, et al. Iron chelation with deferasirox in adult and pediatric patients with thalassemia major: efficacy and safety during 5 years' follow-up. Blood. 2011;118(4):884-893.

25. Olivieri NF, Koren G, Harris J, et al. Growth failure and bony changes induced by deferoxamine. Am J Pediatr Hematol Oncol. 1992;14(1):48-56. 
26. Aydinok Y, Unal S, Oymak Y, et al. Observational study comparing long-term safety and efficacy of deferasirox with desferioxamine therapy in chelation naive children with transfusional iron overload. Eur J Haematol. 2012;88(5):431-438.

27. Pennell DJ, Porter JB, Cappellini MD, et al. Efficacy of deferasirox in reducing and preventing cardiac iron overload in beta-thalassemia. Blood. 2010;115(12):2364-2371.

28. Pennell DJ, Porter JB, Cappellini MD, et al. Deferasirox for up to 3 years leads to continued improvement of myocardial T2* in patients with $\beta$-thalassemia major. Haematologica. 2012;97(6):842-848.

29. Reyal Y, Chowdhury O, Kirk P, et al. Improvement in cardiac T2* with deferasirox in transfused patients with cardiac iron overload [abstract] Haematologica. 2008;93(Suppl 1):846.

30. Deugnier Y, Turlin B, Ropert M, et al. Improvement in liver pathology of patients with $\beta$-thalassemia treated with deferasirox for at least 3 years. Gastroenterology. 2011;141(4):1202-1211.

31. Taher A, El-Beshlawy A, Elalfy MS, et al. Efficacy and safety of deferasirox, an oral iron chelator, in heavily iron-overloaded patients with beta-thalassaemia: the ESCALATOR study. Eur J Haematol. 2009;82(6):458-465.

32. Adams RJ, McKie VC, Hsu L, et al. Prevention of a first stroke by transfusions in children with sickle cell anemia and abnormal results on transcranial Doppler ultrasonography. $N$ Engl J Med. 1998;339(1):5-11.

33. Miller ST, Wright E, Abboud M, et al. Impact of chronic transfusion on incidence of pain and acute chest syndrome during the Stroke Prevention Trial (STOP) in sickle-cell anemia. J Pediatr. 2001;139(6):785-789.

34. Wang WC, Morales KH, Scher CD, et al. Effect of long-term transfusion on growth in children with sickle cell anemia: results of the STOP trial. J Pediatr. 2005;147(2):244-247.

35. Kwiatkowski JL, Cohen AR. Iron chelation therapy in sickle-cell disease and other transfusion-dependent anemias. Hematol Oncol Clin North Am. 2004;18(6):1355-1377.

36. National Institutes of Health. Management and Therapy of Sickle Cell Disease. 3rd ed. Bethesda (MD): National Heart, Lung, and Blood Institute; 1995.

37. Vichinsky E, Onyekwere O, Porter J, et al. A randomised comparison of deferasirox versus deferoxamine for the treatment of transfusional iron overload in sickle cell disease. Br J Haematol. 2007;136(3):501-508.

38. Vichinsky E, Bernaudin F, Forni GL, et al. Long-term safety and efficacy of deferasirox (Exjade) for up to 5 years in transfusional iron-overloaded patients with sickle cell disease. $\mathrm{Br} J$ Haematol. 2011;154(3):387-397.

39. Cancado R, Olivato MC, Bruniera P, et al. Two-year analysis of efficacy and safety of deferasirox treatment for transfusional iron overload in sickle cell anemia patients. Acta Haematol. 2012;128(2):113-118.

40. Greenberg PL, Young NS, Gattermann N. Myelodysplastic syndromes. Hematology Am Soc Hematol Educ Program. 2002:136-161.

41. Porter JB. Practical management of iron overload. Br J Haematol. 2001;115(2):239-252.

42. Cortelezzi A, Cattaneo C, Cristiani S, et al. Nontransferrin-bound iron in myelodysplastic syndromes: a marker of ineffective erythropoiesis. Hematol J. 2000;1(3):153-158.

43. Malcovati L, Della Porta MG, Pascutto C, et al. Prognostic factors and life expectancy in myelodysplastic syndromes classified according to WHO criteria: a basis for clinical decision making. J Clin Oncol. 2005;23(30):7594-7603.

44. Gattermann N, Rachmilewitz. EA Iron overload in MDS - pathophysiology, diagnosis and complications. Ann Hematol. 2011;90(1):1-10.

45. Armand P, Kim HT, Cutler CS, et al. Prognostic impact of elevated pretransplantation serum ferritin in patients undergoing myeloablative stem cell transplantation. Blood. 2007;109(10):4586-4588.

46. Musallam KM, Cappellini MD, Wood JC, et al. Iron overload in non transfusion-dependent thalassemia: a clinical perspective. Blood Rev. 2012;26 Suppl 1:16-19.

47. Gattermann N. Clinical consequences of iron overload in myelodysplastic syndromes and treatment with chelators. Hematol Oncol Clin North Am. 2005;19 Suppl 1:13-17.
48. Alessandrino EP, Amadori S, Barosi G, et al. Evidence- and consensusbased practice guidelines for the therapy of primary myelodysplastic syndromes. A statement from the Italian Society of Hematology. Haematologica. 2002;87(12):1286-1306.

49. Bowen D, Culligan D, Jowitt S, et al. Guidelines for the diagnosis and therapy of adult myelodysplastic syndromes. $\mathrm{Br} J$ Haematol. 2003;120(2):187-200.

50. Gattermann N, Porter JB, Lopes LF, et al. Consensus statement on iron overload in myelodysplastic syndromes. Hematol Oncol Clin North Am. 2005;19 Suppl 1:18-25.

51. National Comprehensive Cancer Network. NCCN Clinical Practice Guidelines in Oncology: Myelodysplastic Syndromes. Version 1.2007. Fort Washington (PA): NCCN; 2007.

52. Porter J, Galanello R, Saglio G, et al. Relative response of patients with myelodysplastic syndromes and other transfusion-dependent anemias to deferasirox (ICL670): a 1-yr prospective study. Eur J Haematol. 2008;80(2):168-176.

53. Metzgeroth G, Dinter D, Schultheis B, et al. Deferasirox in MDS patients with transfusion-caused iron overload - a Phase II study. Ann Hematol. 2009;88(4):301-310.

54. Wimazal F, Nösslinger T, Baumgartner C, Sperr WR, Pfeilstöcker M, Valent P. Deferasirox induces regression of iron overload in patients with myelodysplastic syndromes. Eur J Clin Invest. 2009;39(5):406-411.

55. Nolte F, Hochsmann B, Giagounidis A, et al. Results from a 1-year, open-label, single arm, multi-center trial evaluating the efficacy and safety of oral deferasirox in patients diagnosed with low and int-1 risk myelodysplastic syndrome (MDS) and transfusion-dependent iron overload. Ann Hematol. 2013;92(2):191-198.

56. Gattermann N, Finelli C, Porta MD, et al. Deferasirox in ironoverloaded patients with transfusion-dependent myelodysplastic syndromes: results from the large 1-year EPIC study. Leuk Res. 2010;34(9):1143-1150.

57. List AF, Baer MR, Steensma DP, et al. Deferasirox reduces serum ferritin and labile plasma iron in RBC transfusion-dependent patients with myelodysplastic syndrome. J Clin Oncol. 2012;30(17):2134-2139.

58. Gattermann N, Jarish A, Schlag R, et al. Deferasirox treatment of iron-overloaded chelation-naïve and prechelated patients with myelodysplastic syndromes in medical practice: results from the observational studies eXtend and eXjange. Eur J Haematol. 2012;88(3):260-268.

59. Gattermann N, Finelli C, Della Porta M, et al. Hematologic responses to deferasirox therapy in transfusion-dependent patients with myelodysplastic syndromes. Haematologica. 2012;97(9):1364-1371.

60. Lyons RM, Marek BJ, Paley C, et al. Relationship between chelation and clinical outcomes in 600 lower-risk MDS patients: registry analysis at 36 months. Blood. 2012;120:3800.

61. Pullarkat V. Objectives of iron chelation therapy in myelodysplastic syndromes: more than meets the eye? Blood. 2009;114(26): 5251-5255

62. Cappellini MD, Porter J, El-Beshlawy A, et al. Tailoring iron chelation by iron intake and serum ferritin: the prospective EPIC study of deferasirox in 1744 patients with transfusion-dependent anemias. Haematologica. 2010;95(4):557-566.

63. Lee JW, Yoon SS, Shen ZX, et al. Hematologic responses in patients with aplastic anemia treated with deferasirox: a post hoc analysis from the EPIC study. Haematologica. 2013;98(7):1045-1048.

64. Tunc B, Tavil B, Karakurt N, et al. Deferasirox therapy in children with Fanconi aplastic anemia. J Pediatr Hematol Oncol. 2012;34(4):247-251.

65. Phatak P, Brissot $\mathrm{P}$, Wurster $\mathrm{M}$, et al. A Phase $1 / 2$ dose-escalation trial of deferasirox for treatment of iron overload in HFE-related hereditary hemochromatosis. Hepatology. 2010;52(5):1671-1679.

66. Rouault TA. Iron metabolism in the CNS: implications for neurodegenerative diseases. Nat Rev Neurosci. Epub July 3, 2013.

67. Food and Drug Administration. Exjade (deferasirox): boxed warning. 2010. Available from: http://www.fda.gov/Safety/MedWatch/ SafetyInformation/SafetyAlertsforHumanMedicalProducts/ucm200850. htm. Accessed July 18, 2013. 
Journal of Blood Medicine

\section{Publish your work in this journal}

The Journal of Blood Medicine is an international, peer-reviewed, open access, online journal publishing laboratory, experimental and clinical aspects of all topics pertaining to blood based medicine including but not limited to: Transfusion Medicine; Blood collection, Donor issues, Transmittable diseases, and Blood banking logistics; Immunohematology; Artificial and alternative

Submit your manuscript here: http://www.dovepress.com/Journal-of-blood-medicine-journal

blood based therapeutics; Hematology; Biotechnology/nanotechnology of blood related medicine; Legal aspects of blood medicine; Historical perspectives. The manuscript management system is completely online and includes a very quick and fair peer-review system. Visit http://www.dovepress.com/ testimonials.php to read real quotes from published authors. 